American Journal of Virology 2 (1): 25-35, 2013

ISSN: 1949-0097

(C)2013 Science Publication

doi:10.3844/ajvsp.2013.25.35 Published Online 2 (1) 2013 (http://www.thescipub.com/ajv.toc)

\title{
Herpetic Viral Retinitis
}

\author{
Hidetaka Noma \\ Department of Ophthalmology, Yachiyo Medical Center, Tokyo Women's Medical University, Chiba, Japan
}

Received 2012-05-30, Revised 2012-07-09; Accepted 2013-07-22

\begin{abstract}
Human Herpes Virus (HHV) is a DNA virus and is the most important viral pathogen causing intraocular inflammation. HHV is classified into types 1-8. Among these types, HHV-1, HHV-2, HHV-3 Varicella Zoster Virus (VZV) and HHV-5 Cytomegalovirus (CMV) are known to cause herpetic viral retinitis, including acute retinal necrosis and CMV retinitis. Herpes viral retinitis can be diagnosed from characteristic ocular findings and viral identification by PCR of the aqueous humor. Recently, therapy has become more effective than in the past. Herpes viral retinitis gradually progresses if appropriate treatment is not provided with regard to the patient's immune status. Further advances in diagnostic methods and treatment are required in the future.
\end{abstract}

Keywords: Human Herpes Virus (HHV), Varicella Zoster Virus (VZV), Acute Retinal Necrosis, Polymerase Chain Reaction (PCR), CMV Retinitis, Pathogen Causing Intraocular Inflammation

\section{INTRODUCTION}

Human Herpes Virus (HHV) is a DNA virus and the most important viral pathogen causing intraocular inflammation. It is classified into types 1-8, among which HHV-1, HHV-2, HHV-3 (Varicella Zoster Virus: VZV) and HHV-5 Cytomegalovirus (CMV) are known causes of herpetic viral retinitis. The types of retinitis caused by these viruses include acute retinal necrosis, CMV retinitis and progressive outer retinal necrosis. This purpose of this article is to review Acute Retinal Necrosis (ARN) and CMV retinitis, which we encounter relatively often in the clinic. The differentiating features of these two types of retinitis are outlined in Table 1.

ARN syndrome is infectious retinitis caused by members of the Herpes virus family. It was first described Urayama et al. (1971) in 6 patients with acute panuveitis and retinal arteritis that progressed to diffuse necrotizing retinitis and late-onset rhegmatogenous retinal detachment. Similar findings were subsequently reported in other patients and the term "bilateral acute retinal necrosis" was introduced by Young and Bird (1978). In the 1980s, the etiology of the disease was shown to be infection by HSV and VSV. Widespread adoption of the Polymerase Chain Reaction (PCR) method from early the 1990 made it possible to easily detect the presence of intraocular viruses, after which many cases of ARN were diagnosed. In 1994, the Executive Committee of the American Uveitis Society defined the disease not by the causative agents or patient immune status, but by its clinical characteristics and course (Holland, 1994). Thus, the diagnosis of ARN has been systematized and treatment has improved compared with the past, but the prognosis is still poor. This disease accounts for $0.9-2.6 \%$ of endogenous uveitis worldwide (Baarsma, 2001). ARN syndrome is rare and generally affects healthy, immunocompetent individuals of either sex and any race. However, immunocompromised individuals may also develop ARN syndrome (Friberg and Jost, 1984). The syndrome shows a bimodal age distribution, with peaks at approximately 20 and 50 years of age (Ganatra et al., 2000). 
Table 1. Differentiating features of ARN and CMV retinitis

\begin{tabular}{lll}
\hline & ARN & CMV retinitis \\
\hline Pathogenic virus & HHV-1, HHV-2, VSV & CMV \\
Immune status & Healthy & Immunosuppressed \\
Laterality & Bilateral $30-80 \%$ & Bilateral $30-50 \%$ \\
Visual loss & Severe & Only if it involves the macula \\
Photopsia & Mild to moderate & Mild \\
Floaters & Mild to moderate & Mild \\
Anterior uveitis & Mild to moderate & Mild \\
Vitreous reaction & Significant vitritis & Minimum/no vitritis \\
Retinal involvement & Full thickness & Full thickness involvement with granular border \\
Classic appearance & Late Swiss-cheese & Pizza pie \\
Vasculitis & Common & Not common \\
Retinal hemorrhages & Common & Common in active lesions \\
Retinal detachment & Common & Less common \\
Progression & Rapid & Slow \\
\hline ARN = Acute Retinal Necrosis; CMV & Cytomegalovirus; HHV = Human Herpes Virus; VZV = Varicella Zoster Virus
\end{tabular}

ARN = Acute Retinal Necrosis; CMV = Cytomegalovirus; HHV = Human Herpes Virus; VZV = Varicella Zoster Virus

CMV infection is a major cause of morbidity and mortality in immunocompromised patients. Patients with immunosuppression due to diseases like Acquired Immune Deficiency Syndrome (AIDS) and those with iatrogenic immunosuppression through treatment with chemotherapy and immunomodulators are at risk (Banker, 2008). CMW infection is associated with a variety of conditions, including retinitis, pneumonitis, hepatitis and encephalitis. CMV retinitis was an extremely rare disease before AIDS due to Human Immunodeficiency Virus (HIV) appeared in 1981. However, with the explosion of AIDS patients, the number of patients presenting with CMV retinitis has increased remarkably. In fact, CMV retinitis is the most common intraocular infection in patients with AIDS, affecting approximately $30 \%$ of them at some point in the course of their disease (Hoover et al., 1996). After 1996, the incidence of CMV retinitis decreased sharply in patients receiving Highly Active Anti-Retroviral Treatment (HAART), but Immune Recovery Uveitis (IRU) after HAART has become a new problem for AIDS patients today. Therefore, CMV retinitis remains a major sight-threatening condition in AIDS patients.

\subsection{Pathogenic Viruses}

Multiple members of the Herpes virus family have been identified as the causative agents of ARN syndrome by viral culture, immmunocytochemical studies, retinal biopsy, intraocular antibody production and PCR analysis (Culbertson et al., 1982; Pepose et al., 1992; Boer et al., 1994; Abe et al., 1996; Ganatra et al., 2000; Walters and James, 2001; Tran et al., 2003a). VZV accounts for the majority of cases, while other viruses include HSV-1 and HSV-2. It has been reported that
HSV-1 sacral cord ganglia and causes disease of the lower body after reactivation. In recent years, this separation of both viruses has been found not to be so certain. Also, many questions remain about the mechanisms involved, including the route of infection or the site of latent infection of these viruses. After VSV causes chickenpox with primary infection, the virus remains dormant in spinal ganglia of the host. After reactivation by various factors, herpes zoster develops. Because the territory of the trigeminal ganglion includes the retina, VZV can cause retinitis.

The clinical features are different between HSVARN and VZV-ARN. HSV-ARN has a young age of onset and more mild cases showing susceptibility to antiviral drug therapy compared with VZV-ARN. However, clinical features do not show any differences and it is impossible to differentiate the two diseases from clinical findings. Generally, when VZV infection is involved, the age-related decline of immunocompetence is associated with the onset. It is known that the cellular immune response and delayed skin reaction to VZV decrease with aging (Itoh et al., 2000). In the early period of VZV-ARN, the varicella virus antigen-specific delayed response (which reflects a type 4 allergic reaction to VZV) becomes negative in $60 \%$ of patients and the outcome tends to be worse in such cases. It is possible that cell-mediated immunity for VZV is inhibited in patients with VZV-ARN or else anterior chamber-associated immune privilege allows VZV to be disseminated in the eye (Kezuka et al., 2001).

CMV is a double-str anded DNA virus and is the largest of the herpesviruses with a genome of approximately $230 \mathrm{~kb}$ encoding 160 genes (Ho, 2008). $\mathrm{CMV}$ is a ubiquitous virus and sero-prevalence surveys 
have estimated that $\sim 50 \%$ of the general population have latent infection (Wentworth and Ander, 1971; Griffiths and Polis, 2008). Certain populations, such as homosexual men, have a higher rate of latent infection (estimated at $>90 \%$ ) (Drew et al., 1981). CMV displays strong host specificity and only infects humans. Viral replication occurs in a highly orchestrated cascade that includes immediate early, early and late phases, leading to the assembly of an icosahedral capsid surrounded by a lipid bilayer envelope (Gandhi and Khanna, 2004).

After infection with CMV, hematogenous dissemination occurs as the virus is carried by polymorphonuclear leukocytes and monocytes (Gerna et al., 2004). In immunocompromised persons, CMV can undergo reactivation and hematogenous dissemination to target organs. The majority of patients with newly-diagnosed CMV retinitis have evidence of systemic CMV replication, which can be detected by culture of the blood or urine $(\sim 80 \%)$ or by PCR amplification of blood samples to detect CMV DNA ( 60\%) (Jabs et al., 1998; 2005). The bloodretina barrier is created by the tight junctions of retinal vascular endothelial and RPE cells, but this barrier is circumvented by the virus via endocytosis, with subsequent intracellular replication and latency (Bodaghi et al., 1999). Replication of CMV in the endothelial cells of the retinal vessels compromises the integrity of the blood-retinal barrier, facilitating access of the virus to retinal glial cells and spread toward the RPE with subsequent necrotic destruction of all retinal layers (Rao et al., 1998). Details of the immune derangements in AIDS patients that lead to susceptibility to CMV retinitis are currently under investigation and are not completely understood. HIV-induced retinal microvasculopathy may facilitate access of CMV to retinal glial cells (Harooni et al., 1996). CMV retinitis results in full-thickness retinal necrosis, so the final result of infection is retinal destruction at the infected sites. CMV resides at the border of the lesion and unless there is immune recovery or anti-CMV therapy is administered, the virus spreads into the contiguous retina and the lesions become larger (Pepose et al., 1985). As lesions enlarge, the visual field becomes smaller and damage to the optic nerve or fovea leads to loss of visual acuity.

The route of infection can be classified as (1) transplacental congenital infection or (2) acquired infection, including birth canal infection and infection via breast milk, water, contact with saliva or urine in childhood and sexual transmission after puberty. Congenital infection has long been known to cause cytomegalic inclusion disease that presents with hepatosplenomegaly or microencephaly and CMV retinitis is found in $20-30 \%$ of such cases. With acquired infection, CMV remains dormant in various organs after initial infection and latent infection is asymptomatic. However, persons with a weakened immune system can become ill, including individuals with AIDS, transplant recipients and patients on treatment with chemotherapy or other immunosuppressive agents. CMV reactivation can lead to infection of various organs, including the lungs, gastrointestinal tract, adrenal $\mathrm{gl}$ ands, pancreas, liver, kidneys, brain and retina.

\subsection{Ocular Manifestations}

Early symptoms may be minimal, including irritation, redness, photopsia, periorbital pain and floaters. Initially, regardless of the causative virus, anterior uveitis may present with episcleritis, scleritis, or keratic precipitates that are typically granulomatous but may be stellate (Fisher et al., 1982). An increase of intraocular pressure is found in many cases. Posterior segment manifestations develop within 1-2 days, with the patient having well-demarcated, multifocal yellowish-white peripheral infiltrates at the level of the deep retina and retinal pigment epithelium. Active vasculitis is characterized by vascular sheathing and perivascular intraretinal hemorrhages, which are typically of limited extent in ARN. Obstruction of the central retinal artery is more common than that of the vein and is a contributing factor to severe loss of vision. Over the next few weeks, retinal necrosis becomes confluent and progresses rapidly and circumferentially toward the posterior pole. Although the macula is frequently unaffected, its involvement does not preclude the diagnosis. Vitreous inflammation and debris progress significantly with increasing necrosis and sloughing of the retina. Optic neuritis may also occur during the active phase and this worsens the final visual outcome. Anterior ocular segment inflammation gradually subsides over time, although vitreous opacities progress and viewing the fundus becomes more difficult.

Resolution of ARN begins approximately 3 weeks after the initiation of treatment. In untreated patients, inflammation wanes from 6-12 weeks after the onset of symptoms (Fisher et al., 1982). Retinal necrosis gradually progresses to retinal thinning and atrophy, which begins at the periphery and moves centrally. Pigmentary changes produce a well-demarcated scalloped line between the normal and involved parts of the retina. The vitreous opacities that initially increased 
begin to resolve from a certain point and the disease seems to be in remission. During this phase, the vitreous fluid is still affected by inflammation, posterior vitreous detachment occurs and vitreous organization and traction continue to progress. Ultimately, both retinal necrosis and secondary proliferative vitreoretinopathy contribute to the development of retinal holes, which typically appear at the junction of the normal and affected parts of the retina. Rhegmatogenous retinal detachment is a common late sequela, occurring in $50-75 \%$ of eyes at $1-2$ months after the onset of retinitis. This retinal detachment is a secondary change caused by retinal necrosis rather than ARN itself, but is a major reason for the poor visual prognosis of this disorder.

Presenting symptoms depend on the location of the retinal lesions and small peripheral lesions may be initially asymptomatic. Nevertheless, in a recent retrospective analysis of HIV-positive patients, a higher percentage of those with documented CMV retinitis had visual symptoms at the time of diagnosis compared with matched control HIV-positive patients without CMV retinitis (88 Vs. 53\%, respectively) (Wei et al., 2002). The most common presenting symptoms are decreased visual acuity (67), floaters (49), photopsia (16), eye pain (7) and scotomas (3\%) (Hodge et al., 2004). In a recent study of 648 AIDS patients with CMV retinitis, $17 \%$ had a visual acuity of $20 / 200$ or worse (blindness) at the time of diagnosis (Kempen et al., 2003). The Fig. 1 shows the mechanisms by which CMV retinitis causes loss of vision in the early and late stages of infection.

The eye affected by CMV retinitis is usually white and quiet. Slit lamp examination may reveal mild signs of inflammation, including fine keratic precipitates and anterior chamber cells. Vitritis, if present at all, is typically minimal. Vascular sheathing is unusual, but if it occurs, it can lead to the striking appearance of frosted branch angiitis (Walker et al., 2003). Papillitis occurs in up to 4\% of patients with CMV retinitis either through primary involvement of the optic nerve or through spread from the peripapillary retina (Mansour, 1997). The resulting CMV optic neuritis leads to rapid loss of vision if untreated, but the visual prognosis is good if the patient is treated promptly and aggressively (Patel et al., 1996).

Because CMV retinitis involves direct retinal invasion by the virus, there is little evidence of anterior segment inflammation or vitritis, but the chorio-retinal changes of CMV retinitis can be diverse. Traditionally, 3 patterns of active lesions have been described:

- Hemorrhagic-predominant retinal hemorrhages interspersed with retinal necrosis
- Brush fire-a progressively exp anding yellow-white margin surrounding an area of necrotic retina

- Granular-a central atrophic area surrounded by punctate white granular satellite lesions without retinal hemorrhage

This classification is somewhat arbitrary as several forms may be observed concurrently in the same patient and even in the same lesion.

CMV retinitis with full-thickness retinal necrosis predisposes the affected eye to rhegmatogenous retinal detachment. This has been reported in 33 of eyes and $50 \%$ of patients within the first year after diagnosis of CMV retinitis (SOCAACTG, 1997). The use of HAART to treat AIDS has led to a $60 \%$ reduction in the incidence of $\mathrm{CMV}$ retinitis-associated retinal detachment, (Kempen et al., 2001) but detachment remain a significant complication that can occur bilaterally, especially in patients who fail to show immune reconstitution (Jabs et al., 2004). These patients have a granular exudative border between the lesion and the normal retinal, which is called granular border.

\subsection{Diagnosis}

Diagnosis of ARN syndrome is solely based on the clinical appearance and course. Over time and with a better underst anding of its pathophysiology, laboratory tests have also become available. The American Uveitis Society has established st andard clinical criteria for the diagnosis of ARN (Holland, 1994). These diagnostic criteria include: (1) one or more discrete foci of retinal necrosis in the periphery, (2) rapid disease progression in the absence of therapy, (3) circumferential progression of necrosis, (4) evidence of occlusive vasculopathy and (5) a prominent vitreous or anterior chamber inflammatory reaction. However, despite these diagnostic criteria, difficulty can still exist in assigning a definite etiology to many cases of posterior uveitis. After the discovery that human herpes viruses were responsible for $A R N$, clinicians tried to use serum antibody titers for diagnosis (fluorescein antibody technique and complement fixation), but this proved to be difficult due to the high prevalence of seropositivity for these viruses in all populations. Ocular reactivation of the virus is not necessarily reflected by an increase of the serum antibody titer (Yoshihiko and Hiroshi, 2008). Thus, atypical presentations remain a diagnostic challenge and delay in treatment can be detrimental to vision. In such cases, laboratory tests on aqueous or vitreous specimens may be beneficial. 


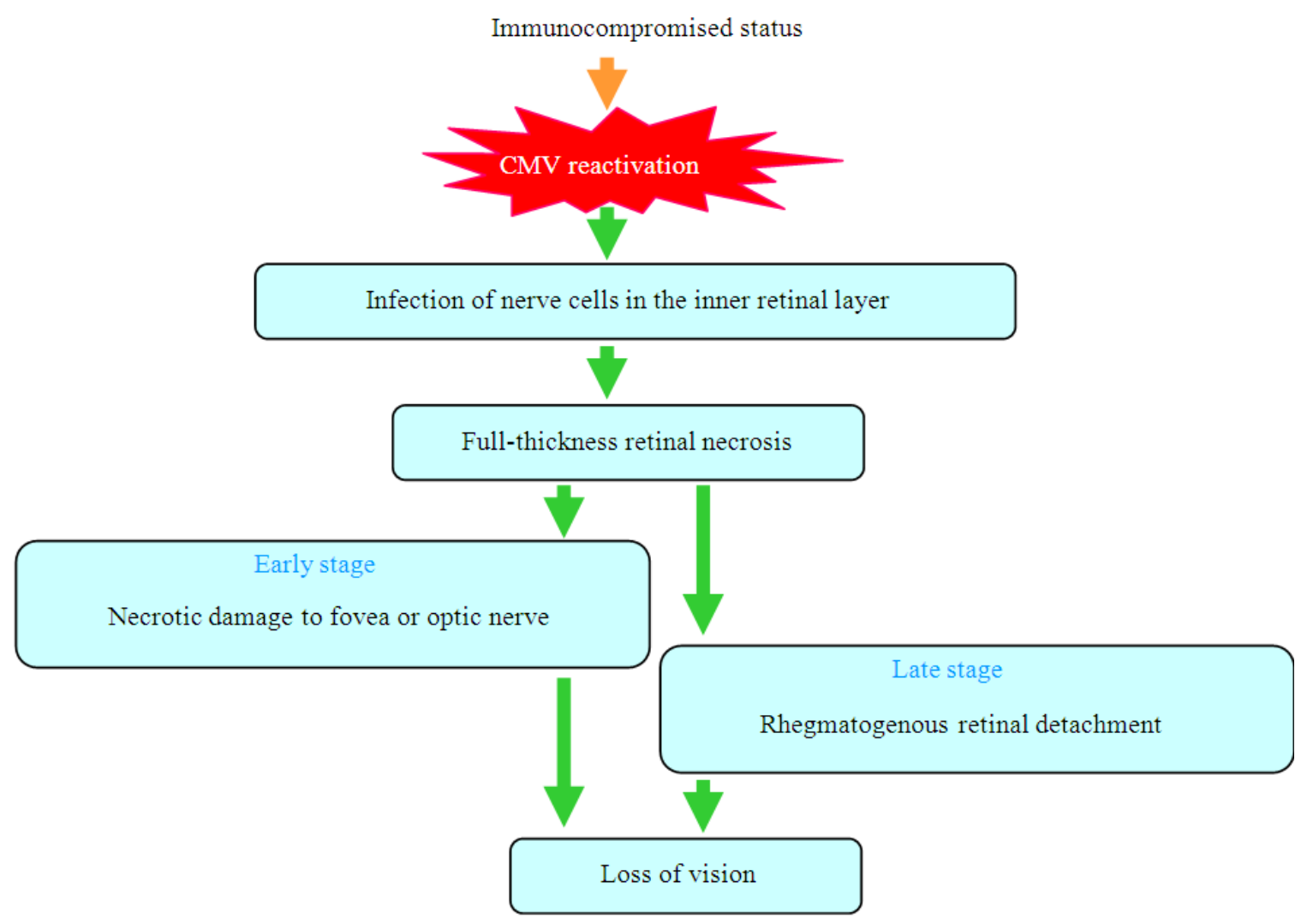

Fig. 1. Mechanism by which CMV retinitis causes loss of vision in the early and late stages of infection

Conventional approaches, such as viral culture, are often time-consuming and have a low yield due to the small volume of intraocular aspirates. PCR is a useful diagnostic tool (Tran et al., 2003a). It is highly sensitive, specific and rapid and only requires a small sample volume. PCR analysis of aqueous humor can be especially helpful and is important in patients with posterior uveitis of unknown etiology. Investigators have reported successful detection of $\mathrm{HHV}$ in $100 \%$ of patients with ARN using both aqueous and vitreous samples, with VZV being detected more commonly than HSV (Sugita et al., 2008). One problem with PCR, however, was whether a virus could be considered as the etiology even if a positive result was obtained because this test only determined the presence or absence of viral DNA. However, real-time PCR has become available that allows the demonstration of high viral copy numbers in patients with ARN (Sugita et al., 2008; Asano et al., 2004). Repeated testing with real-time PCR can also predict the effect of treatment and the prognosis.
The diagnosis of CMV retinitis is easy based on the characteristic fundus findings. The diagnosis becomes certain if we can confirm ocular and systemic CMV infection as well as an immunodeficient state. As a proof of ocular CMV infection, it is most useful to detect CMV DNA by PCR of aqueous humor. Because the quantity of viral DNA can be assessed when we use real-time PCR, the effect of treatment can be determined (Sugita et al., 2008). It has not been reported that CMV retinitis was diagnosed by direct isolation and culture because culture is difficult due to the small viral load. Blood tests are also not very helpful. Detection of IgG antibody only shows a history of infection. Although IgG antibody may become positive when a person with latent CMV infection develops immunodeficiency, CMV antigenemia only reflects CMV activity systemically, so we cannot diagnose ocular lesions as CMV retinitis just because antigenemia is positive. This is because antigenemia will become positive if $\mathrm{CMV}$ infection occurs in other organs. In contrast, we cannot reject 
CMV retinitis if CMV antigenemia is negative because this often occurs in patients with CMV retinitis. As other blood tests, the number of CD4-positive $\mathrm{T}$ lymphocytes in the peripheral blood is often less than $50 \mathrm{~mm}^{-3}$ in patients with AIDS (Hoover et al., 1996). However, after HAART (which combines a protease inhibitor with a reverse transcriptase inhibitor), CMV retinitis may occur even if the number of CD4-positive cellss is $50 \mathrm{~mm}^{-3}$ or more. In the patients without AIDS, there is no useful blood test for CMV retinitis. However, it could be diagnosed if they are taking anticancer or immunosuppressive therapy.

\subsection{Differential Diagnosis}

Various infectious conditions (ARN, progressive outer retinal necrosis (PORN), CMV retinitis, Behcet disease and sarcoidosis) can present with necrotizing retinitis, making correct diagnosis and selection of appropriate treatment difficult. With most of these conditions, the differential diagnosis does not have a major influence on the visual prognosis, even if there is some delay before definitive treatment is given. However, delayed treatment of ARN has a marked influence on the visual prognosis. When we encounter panuveitis with yellowish white retinal lesions, it is initially important to rapidly decide "whether it is ARN or not". Expansion of the exudates is slow in diseases other than ARN and often occurs over a period of several weeks. On the other hand, ARN progresses more rapidly and new lesions can often be clearly seen on the next day. Because a diagnosis may be reached before obtaining the results of various tests, it is important to observe patients on a daily basis.

PORN is another necrotizing herpetic retinopathy and is a distinct clinical entity that occurs in patients with acquired immunodeficiency syndrome (Engstrom et al., 1994; Gariano et al., 2001). ARN tends to occur in immunocompetent or mildly immunocompromised patients, whereas PORN is usually associated with advanced AIDS. Although VZV and HSV are causative agents for both PORN and ARN syndrome, the clinical course and features are different (Mendelsohn and Jampol, 1984). Retinal arteritis completes the clinical triad of ARN. In PORN, the outer retina is primarily affected. Initially, there are deep multifocal patches of retinal whitening and necrosis that extend throughout the peripheral retina. Macular involvement also often occurs early. As in ARN syndrome, the optic nerve may be affected too. Widespread retinal necrosis and atrophy develop rapidly. In contrast to ARN syndrome, there is little or no occlusive vasculitis and inflammation of the anterior chamber or vitreous fluid. As more patients undergo diagnostic vitrectomy to establish the etiology of necrotizing retinopathy, it has been found that the clinical features do not always allow simple categorization, with cases of PCR-proven CMV infection being reported for both ARN (Akpek et al., 1999) and PORN (Biswas et al., 2002). Management is difficult, often requiring long-term treatment with multiple systemic agents and intravitreal antiviral therapy.

Although CMV is the most common cause of necrotizing retinitis, the clinical picture and ocular lesions caused by other opportunistic infections in immunocompromised patients may be very similar (Vrabec, 2004). Necrotizing herpetic retinopathy is a clinical spectrum of posterior uveitis and retinitis that is subdivided into ARN and PORN. Typically, ARN and PORN show rapid progression, unlike CMV retinitis. Furthermore, vitritis is minimal or absent in CMV retinitis, while ARN usually features severe vitritis and anterior uveitis with anterior chamber cells and keratic precipitates.

In addition, we can easily differentiate Behcet disease (broom-shaped vasculitis) and sarcoidosis (nodosity periphlebitis) by the characteristic features of vasculitis on fluorescein angiography.

\subsection{Antiviral Therapy}

The goal of medical therapy is rapid recovery and preventing involvement of the other eye. First, systemic therapy with acyclovir is selected because of its efficacy and safety. Acyclovir is a guanine analog with activity against HSV-1, HSV-2 and VZV (Teich et al., 1992). It selectively inhibits DNA polymerase and requires a virus-specific thymidine kinase for activation. Thus, it only targets HSV-1-, HSV-2-and VZV-infected cells and has limited toxicity for normal cells. Other anti-HSV agents include valacyclovir, (Emerson et al., 2006; Huynh et al., 2008) famcyclovir, (Emerson et al., 2006; Aizman et al., 2007) and foscarnet (Tran et al., 2003b; King et al., 2007; Patel et al., 2010). The recommended treatment consists of induction with $15 \mathrm{mg} \mathrm{kg} \mathrm{kgy}^{-1}$ intravenous of acyclovir in 3 divided doses for 7-10 days because the drug levels achieved after oral administration may be 
subtherapeutic. Oral antiviral medication is then continued with either acyclovir (800 mg 5 times a day), valacyclovir (1 g 3 times a day), or famcyclovir (500 mg 3 times a day).

The success or failure of treatment has great meaning from the viewpoint of quality of life and vision because CMV retinitis causes visual loss if it is untreated. CMV retinitis usually occurs in AIDS patients when the CD4-positive T-cell count is below 50 cells $/ \mathrm{mm}^{3,5}$ developing at a rate of 0.20 cases per person-year among patients with a count below 50 cells $\mathrm{mm}^{-3}$ (Hoover et al., 1996; Pertel et al., 1992). If left untreated, it may cause progressive destruction of retinal tissue and irreversible visual loss. The goal of treatment is to preserve vision and prevent further progression. Treatment of CMV retinitis usually consists of an induction phase and a maintenance phase. During the induction phase, drugs are usually given for 2-3 weeks or until a clinical response is noted. After the induction phase comes the maintenance phase, in which drug dosages are reduced and there is careful monitoring of any signs of reactivation. Lifelong maintenance therapy for CMV retinitis is needed if the CD4-positive $\mathrm{T}$ cell count is $<100$ cells $\mathrm{mm}^{-3}$. The Centers for Disease Control recommends that therapy can be discontinued when the count remains above 100-150 cells $\mathrm{mm}^{-3}$ for $>6$ months in response to HAART (Kaplan et al., 2009). Medical treatment for CMV retinitis includes oral, intravenous and intravitreal agents. Treatment is individualized, depending upon the location of the active retinitis and the immune status of the patient. Currently available anti-CMV agents include ganciclovir (Faulds and Heel, 1990; Dunn and Jabs, 1996; Noble and Faulds, 1998; McGavin and Goa, 2001; Lalezari et al., 2002a) and its prodrug valganciclovir, (Lalezari et al., 2002b) foscarnet, (SOCAIDSRGCACTG, 1992; Jacobson, 1992; SOCAIDSRGCACTG, 1994; Ohta et al., 2001) cidofovir, (Lalezari et al., 1995; Kirsch et al., 1995; Akler et al., 1998; TSOCAIDSRGCAIDSCTG, 2000) fomivirsen, (Stone and Jaffe, 2000; AIDS, 2002a; 2002b) implant, (Martin et al., 1997; Vrabec et al., 1998; Hatton et al., 1998) oral valganciclovir (Lalezari et al., 2002a). A brief summary of these drugs is provided in Table 2.

Table 2. Medications for cytomegalovirus retinitis

\begin{tabular}{|c|c|c|c|c|}
\hline Medication & Route & Induction dose & Maintenance dose & Adverse effects \\
\hline \multirow[t]{4}{*}{ Ganciclovir } & Intravenous & $\begin{array}{l}5 \mathrm{mg} \mathrm{kg}^{-1} \text { twice daily } \\
\text { for } 2-3 \text { weeks }\end{array}$ & $5 \mathrm{mg} / \mathrm{kg} /$ day indefinitely & $\begin{array}{l}\text { Neutropenia, anemia, } \\
\text { thrombocytopenia, renal failure }\end{array}$ \\
\hline & Oral & Not used & 3-6 $\mathrm{g} \mathrm{day}^{-1}$ indefinitely & Same as above \\
\hline & Intravitreal & $400 \mu \mathrm{g}$ twice/week & $400 \mu \mathrm{g}$ once/week & $\begin{array}{l}\text { Vitreous hemorrhage, retinal } \\
\text { detachment }\end{array}$ \\
\hline & Implant & $\begin{array}{l}6 \text { mg pellet inserted } \\
\text { surgically through a } \\
\text { pars plana incision }\end{array}$ & $\begin{array}{l}\text { Replaced every } 5-8 \\
\text { months }\end{array}$ & $\begin{array}{l}\text { Vitreous hemorrhage, retinal } \\
\text { detachment, cataract, } \\
\text { endophthalmitis, CME }\end{array}$ \\
\hline Valganciclovir & Oral & $\begin{array}{l}900 \mathrm{mg} \text { twice daily } \\
\text { for } 3 \text { weeks }\end{array}$ & $900 \mathrm{mg} / \mathrm{d}$ & $\begin{array}{l}\text { Neutropenia, anemia, } \\
\text { thrombocytopenia, gastric } \\
\text { disturbances }\end{array}$ \\
\hline \multirow[t]{2}{*}{ Foscarnet } & Intravenous & $\begin{array}{l}90 \mathrm{mg} \mathrm{kg}^{-1} \text { twice daily } \\
\text { for } 2-3 \text { weeks }\end{array}$ & $90-120 \mathrm{mg} / \mathrm{kg} / \mathrm{d}$ indefinitely & $\begin{array}{l}\text { Elevated creatinine, decreased } \\
\mathrm{Ca}, \mathrm{Mg}, \mathrm{K} \text {; tetany, perioral } \\
\text { numbness, finger parasthesia }\end{array}$ \\
\hline & Intravitreal & $2400 \mu \mathrm{g}$ twice/week & $2400 \mu \mathrm{g}$ once/week & $\begin{array}{l}\text { Vitreous hemorrhage, retinal } \\
\text { detachment }\end{array}$ \\
\hline \multirow[t]{2}{*}{ Cidofovir } & Intravenous & $\begin{array}{l}5 \mathrm{mg} \mathrm{kg}^{-1} \text { weekly for } \\
2 \text { weeks }\end{array}$ & $3-5 \mathrm{mg} \mathrm{kg}^{-1}$ every other week & $\begin{array}{l}\text { Proteinuria, renal failure, } \\
\text { Fanconis syndrome, neutropenia, } \\
\text { uveitis, hypotony }\end{array}$ \\
\hline & Intravitreal & $15 \mu \mathrm{g} / 0.1 \mathrm{~mL}$ & $15 \mu \mathrm{g} / 0.1 \mathrm{~mL}$ every 6 weekly & $\begin{array}{l}\text { Uveitis, hypotony, IRU, vitreous } \\
\text { hemorrhage, retinal detachment }\end{array}$ \\
\hline Fomivirsen & Intravitreal & $330 \mu \mathrm{g}$ on days 1 and 15 & $330 \mu \mathrm{g}$ monthly & $\begin{array}{l}\text { Uveitis, vitreous hemorrhage, } \\
\text { retinal detachment }\end{array}$ \\
\hline
\end{tabular}

$\overline{\mathrm{CME}}=$ Cystoid Macular Edema; IRU = Immune Recovery Uveitis 


\section{CONCLUSION}

Herpes viral retinitis can be diagnosed from characteristic ocular findings and viral identification by PCR of the aqueous humor. Therapy has become more effective than in the past. However, herpes viral retinitis gradually progresses if appropriate treatment is not provided, depending on the patient's immune status. Further advances in diagnostic methods and treatment are expected in the future.

\section{REFERENCES}

Abe, T., K. Tsuchida and M. Tamai, 1996. A comparative study of the polymerase chain reaction and local antibody production in acute retinal necrosis syndrome and cytomegalovirus retinitis. Graefes. Arch Clin. Exp. Ophthalmol., 234: 419424. PMID: 8817284

AIDS, 2002a. $\mathrm{R}$ andomized controlled clinical trial of intravitreous fomivirsen for treatment of newly diagnosed peripheral cytomegalovirus retinitis in patients with AIDS. Am. J. Ophthalmol., 133: 467474. PMID: 11931780

AIDS, 2002b. R andomized dose-comparison studies of intravitreous fomivirsen for treatment of cytomegalovirus retinitis that has reactivated or is persistently active despite other therapies in patients with AIDS. Am. J. Ophthalmol., 133: 475-483. PMID: 11931781

Aizman, A., M.W. Johnson and S.G. Elner, 2007. Treatment of acute retinal necrosis syndrome with oral antiviral medications. Ophthalmology, 114: 307-312. PMID: 17123607

Akler, M.E., D.W. Johnson, W.J. Burman and S.C. Johnson, 1998. Anterior uveitis and hypotony after intravenous cidofovir for the treatment of cytomegalovirus retinitis. Ophthalmology, 105: 651657. DOI:10.1016/S0161-6420(98)94019-2.

Akpek, E.K., C. Kent, F. Jakobiec, A.M. Caliendo and C.S. Foster, 1999. Bilateral acute retinal necrosis caused by cytomegalovirus in an immunocompromised patient. Am. J. Ophthalmol., 127: 93-95. PMID: 9933010

Asano, S., T. Yoshikawa, H. Kimura, Y. Enomoto and M. Ohashi et al., 2004. Monitoring herpesviruses DNA in three cases of acute retinal necrosis by realtime PCR. J. Clin. Virol., 29: 207-210. DOI: 10.1016/S1386-6532(03)00162-8
Baarsma, G.S., 2001. The epidemiology and genetics of endogenous uveitis: A review. Curr. Eye. Res., 11: 1-9. PMID: 1424734.

Banker, A.S., 2008. Posterior segment manifestations of human immunodeficiency virus/acquired immune deficiency syndrome. Ind. J. Ophthalmol., 56: 377383. DOI: $10.4103 / 0301-4738.42413$

Biswas, J., S. Choudhry, K. Priya and L. Gopal, 2002. Detection of cytomegalovirus from vitreous humor in a patient with progressive outer retinal necrosis. Indian. J. Ophthalmol., 50: 319-321. PMID: 12532499

Bodaghi. B., M.E.P. Slobbe-vanDrunen, A. Topilko, E. Perret and R.C.R.M. Vossen et al., 1999. Entry of human cytomegalovirus into retinal pigment epithelial and endothelial cells by endocytosis. Invest. Ophthalmol. Vis. Sci., 40: 2598-2607.

Boer, J.H.D. L. Luyendijk, A. Rothova, G.S. Baarsma and P.T.D. Jong et al., 1994. Detection of intraocular antibody production to herpesviruses in acute retinal necrosis syndrome. Am. J. Ophthalmol., 117: 201-210. PMID: 8116748

Culbertson, W.W. M.S. Blumenkranz, H. Haines, D.M. Gass and K.B. Mitchell et al., 1982. The acute retinal necrosis syndrome. Part 2: Histopathology and etiology. Ophthalmology, 89: 1317-1325. PMID: 6298683

Drew, W.L., L. Mintz, R.C. Miner, M. Sands and B. Ketterer, 1981. Prevalence of cytomegalovirus infection in homosexual men. J. Infect. Dis., 143: 188-192. DOI: 10.1093/infdis/143.2.188

Dunn, J.P. and D.A. Jabs, 1996. Cytomegalovirus retinitis in AIDS: Natural history, diagnosis and treatment. AIDS Clin. Rev., 99-129. PMID: 7488562

Emerson, G.G., J.R. Smith, D.J. Wilson, J.T. Rosenbaum and C.J. Flaxel, 2006. Primary treatment of acute retinal necrosis with oral antiviral therapy. Ophthalmology, 113: 2259-2261. DOI: 10.1016/j.ophtha.2006.05.063

Engstrom, R.E., G.N. Holland, T.P. Margolis, C. Muccioli and J.I. Lindley et al., 1994. The progressive outer retinal necrosis syndrome. A variant of necrotizing herpetic retinopathy in patients with AIDS. Ophthalmology, 101: 14881502. PMID: 8090452

Faulds, D. and R.C. Heel, 1990. Ganciclovir. A review of its antiviral activity, pharmacokinetic properties and therapeutic efficacy in cytomegalovirus infections. Drugs, 39: 597-638. PMID: 2161731 
Fisher, J.P., M.L. Lewis, M. Blumenkranz, W.W. Culbertson and H.W. Flynn Jr et al., 1982. The acute retinal necrosis syndrome. Part 1: Clinical manifestations. Ophthalmology, 89: 1309-1316. PMID: 7162777

Friberg, T.R. and B.F. Jost, 1984. Acute retinal necrosis in an immunosuppressed patient. Am. J. Ophthalmol., 98: 515-517. PMID: 6486231

Ganatra, J.B., D. Ch andler, C. Santos, B. Kuppermann and T.P. Margolis et al., 2000. Viral causes of the acute retinal necrosis syndrome. Am. J. Ophthalmol., 129: 166-172. DOI: 10.1016/S0002-9394(99)00316-5

Gandhi, M.K. and R. Khanna, 2004. Human cytomegalovirus: Clinical aspects, immune regulation and emerging treatments. Lancet Infect. Dis., 4: 725-238. DOI: 10.1016/S14733099(04)01202-2

Gariano, R.F., J.P. Berreen and E.L. Cooney, 2001. Progressive outer retinal necrosis and acute retinal necrosis in fellow eyes of a patient with acquired immunodeficiency syndrome. Am. J. Ophthalmol., 132: 421-423. PMID: 11530066

Gerna, G., F. Baldanti and M.G. Revello, 2004. Pathogenesis of human cytomegalovirus infection and cellular targets. Hum. Immunol., 65: 381-386. DOI: 10.1016/j.humimm.2004.02.009

Griffiths, P.D. and M.A. Polis, 2008. Cytomegalovirus Disease. In: AIDS Therapy, Dolin, R., H. Masur and M. Saag (Eds.), Churchill Livingstone, Philadelphia Elsevier, ISBN-10: 044306752X, pp: 855-884.

Harooni, M., K. Lashkari, J.M. Freilich and C.L. Schepens, 1996. Cytomegalovirus retinitis. Int. Ophthalmol. Clin., 36: 131-40.

Hatton, M.P., J.S. Duker, E. Reichel, M.G. Morley and C.A. Puliafito, 1998. Treatment of relapsed cytomegalovirus retinitis with the sustained-release ganciclovir implant. Retina, 18: 50-55. PMID: 9502281

Ho, M., 2008. The history of cytomegalovirus and its diseases. Med. Microbiol. Immunol., 197: 65-73. PMID: 18087722

Hodge, W.G., J.F. Boivin, S.H. Shapiro, R.G. Lalonde and K.C. Shah et al., 2004. Clinical risk factors for cytomegalovirus retinitis in patients with AIDS. Ophthalmology, 111: 1326-1333. PMID: 15234132

Holland, G.N., 1994. St andard diagnostic criteria for the acute retinal necrosis syndrome. Executive Committee of the American Uveitis. Soc. Am. J. Ophthalmol., 117: 663-667. PMID: 8172275.
Hoover, D.R., Y. Peng. A. Saah, R. Semba and R.R. Detels et al., 1996. Occurrence of cytomegalovirus retinitis after human immunodeficiency virus immunosuppression. Arch. Ophthalmol., 114: 821827. DOI: 10.1001/archopht.1996.01100140035004

Huynh, T.H., M.W. Johnson, G.M. Comer and D.N. Fish, 2008. Vitreous penetration of orally administered valacyclovir. Am. J. Ophthalmol., 145: 682-686. DOI: 10.1016/j.ajo.2007.11.016

Itoh, N., N. Matsumura, A. Ogi, T. Nishide and Y. Imai et al., 2000. High prevalence of herpes simplex virus type 2 in acute retinal necrosis syndrome associated with herpes simplex virus in Japan. Am. J. Ophthalmol., 129: 404-405. PMID: 10704570

Jabs, D.A., B.K. Martin, M.S. Forman and M.O. Ricks, 2005. Cytomegalovirus (CMV) blood DNA load, $\mathrm{CMV}$ retinitis progression and occurrence of resistant CMV in patients with CMV retinitis. J. Infect. Dis., 192: 640-649. PMID: 16028133

Jabs, D.A., C. Enger, J.P. Dunn, M. Forman and L. Hubbard, 1998. Cytomegalovirus retinitis and viral resistance: 3. Culture results. CMV Retinitis and Viral Resistance Study Group. Am. J. Ophthalmol., 126: 543-549. DOI: 10.1086/514249

Jabs, D.A., M.L.V. Natta, J.E. Thorne, D.V. Weinberg and T.A. Meredith et al., 2004. Course of cytomegalovirus retinitis in the era of highly active antiretroviral therapy: 2. Second eye involvement and retinal detachment. Ophthalmology, 111: 22322239. PMID: 15582079

Jacobson, M.A., 1992. Review of the toxicities of foscarnet. J. Acquir. Immune. Defic. Syndr., 5: 11-17.

Kaplan, J.E., C. Benson, K.H. Holmes, J.T. Brooks, A. Pau and H. Masur, 2009. Guidelines for prevention and treatment of opportunistic infections in HIVinfected adults and adolescents: Recommendations from CDC, the National Institutes of Health and the HIV Medicine Association of the Infectious Diseases Society of America. MMWR Recomm. Rep., 58: 201-207. PMID: 19357635

Kempen, J.H., D.A. Jabs, J.P. Dunn, S.K. West and J. Tonascia, 2001. Retinal detachment risk in cytomegalovirus retinitis related to the acquired immunodeficiency syndrome. Arch Ophthalmol., 119: 33-40. PMID: 11146724

Kempen, J.H., D.A. Jabs, L.A. Wilson, J.P. Dunn and S.K. West et al., 2003. Risk of vision loss in patients with cytomegalovirus retinitis and the acquired immunodeficiency syndrome. Arch. Ophthalmol., 121: 466-476. DOI: 10.1001/archopht.121.4.466 
Kezuka, T., J. Sakai, N. Usui, J.W. Streilein and M. Usui, 2001. Evidence for antigen-specific immune deviation in patients with acute retinal necrosis. Arch Ophthalmol., 119: 1044-1049. PMID: 11448326

King, J., M. Chung and D.A. Jr. DiLoreto, 2007. A 9 year-old girl with herpes simplex virus type 2 acute retinal necrosis treated with intravitreal foscarnet. Ocul. Immunol. Inflamm., 15: 395-398. PMID: 17972224

Kirsch, L.S., J.F. Arevalo, D.L. Chavez, E. Paz and D. Munguia et al., 1995. Intravitreal cidofovir (HPMPC) treatment of cytomegalovirus retinitis in patients with acquired immune deficiency syndrome. Ophthalmology, 102: 533-542. PMID: 7724170

Lalezari, J., J. Lindley, S. Walmsley, B. Kuppermann and M. Fisher et al., 2002a. A safety study of oral valganciclovir maintenance treatment of cytomegalovirus retinitis. J. Acquir. Immune. Defic. Syndr., 30: 392-400.

Lalezari, J.P., D.N. Friedberg, J. Bissett, M.F. Giordano and W.D. Hardy et al., 2002b. High dose oral ganciclovir treatment for cytomegalovirus retinitis. J. Clin. Virol., 24: 67-77.

Lalezari, J.P., W.L. Drew, E. Glutzer, C. James and D. Miner et al., 1995. (S)-1-[3-hydroxy-2(phosphonylmethoxy)propyl]cytosine (cidofovir): Results of a phase I/II study of a novel antiviral nucleotide analogue. J. Infect. Dis., 171: 788-796.

Mansour, A.M., 1997. Cytomegalovirus optic neuritis. Curr. Opin. Ophthalmol., 8: 55-58. PMID: 10168894

Martin, D.F., F.L. Ferris, D.J. Parks, R.C. Walton and S.D. Mellow et al., 1997. Ganciclovir implant exchange: Timing, surgical procedure and complications. Arch. Ophthalmol., 115: 1389-1394. DOI: 10.1001/archopht.1997.01100160559005

McGavin, J.K. and K.L. Goa, 2001. Ganciclovir: An update of its use in the prevention of cytomegalovirus infection and disease in transplant recipients. Drugs, 61: 1153-1183. PMID: 11465876

Mendelsohn, A.D. and L.M. Jampol, 1984. Syphilitic retinitis. A cause of necrotizing retinitis. Retina, 4: 221-224. PMID: 6531516

Noble, S. and D. Faulds, 1998. Ganciclovir. An update of its use in the prevention of cytomegalovirus infection and disease in transplant recipients. Drugs, 56: 115-146. PMID: 9664203
Ohta, H., Y. Matsuda, S. Tokimasa, A. Sawada and J.Y. Kim et al., 2001. Foscarnet therapy for ganciclovirresistant cytomegalovirus retinitis after stem cell transplantation: Effective monitoring of CMV infection by quantitative analysis of CMV mRNA. Bone Marrow Transplant, 27: 1141-1145. PMID: 11551024

Patel, P., E. Ahmed and M.L. Subramanian, 2010. Intravitreal foscarnet therapy for acyclovir-resistant acute retinal necrosis after herpes simplex encephalitis. Ophthalmic Surg. Lasers Imag., 9: 1-3. PMID: 20337281

Patel, S.S., A.R. Rutzen, J.L. Marx, A.B. Thach, L.P. Chong and N.A. Rao, 1996. Cytomegalovirus papillitis in patients with acquired immune deficiency syndrome. Visual prognosis of patients treated with ganciclovir and/or foscarnet. Ophthalmology, 103: 1476-1482. PMID: 8841309

Pepose, J.S. B. Flowers, J.A. Stewart, C. Grose and D.S. Levy et al., 1992. Herpesvirus antibody levels in the etiologic diagnosis of the acute retinal necrosis syndrome. Am. J. Ophthalmol., 113: 248-256. PMID: 1311902

Pepose, J.S., G.N. Holland, M.S. Nestor, A.J. Cochran and R.Y. Foos, 1985. Acquired immune deficiency syndrome. Pathogenic mechanisms of ocular disease. Ophthalmology, 92: 472-484. PMID: 2987769

Pertel, P., R. Hirschtick, J. Phair, J. Chmiel and L. Poggensee et al., 1992. Risk of developing cytomegalovirus retinitis in persons infected with the human immunodeficiency virus. J. Acquir. Immune. Defic. Syndr., 5: 1069-1074.

Rao, N.A., J. Zhang and S. Ishimoto, 1998. Role of retinal vascular endothelial cells in development of CMV retinitis. Trans. Am. Ophthalmol. Soc., 96: 111-126. PMID: PMC1298391

SOCAACTG, 1997. Rhegmatogenous retinal detachment in patients with cytomegalovirus retinitis: The Foscarnet-Ganciclovir Cytomegalovirus Retinitis Trial. Am. J. Ophthalmol., 124: 61-70. PMID: 9222234

SOCAIDSRGCACTG, 1992. Mortality in patients with the acquired immunodeficiency syndrome treated with either foscarnet or ganciclovir for cytomegalovirus retinitis. N. Engl. J. Med., 326: 213-220. DOI: 10.1056/NEJM199201233260401

SOCAIDSRGCACTG, 1994 Foscarnet-Ganciclovir Cytomegalovirus Retinitis Trial. 4. Visual outcomes. Ophthalmology, 101: 1250-1261. PMID: 8035989 
Stone, T.W. and G.J. Jaffe, 2000. Reversible bull's-eye maculopathy associated with intravitreal fomivirsen therapy for cytomegalovirus retinitis. Am. J. Ophthalmol., 130: 242-243.

Sugita, S., N. Shimizu, K. Watanabe, M. Mizukami and T. Morio et al., 2008. Use of multiplex PCR and real-time PCR to detect human herpes virus genome in ocular fluids of patients with uveitis. Br. J. Ophthalmol., 92: 928-932. PMID: 18408082

Teich, S.A., T.W. Cheung and A.H. Friedman, 1992. Systemic antiviral drugs used in ophthalmology. Surv. Ophthalmol., 37: 19-53. DOI: 10.1016/00396257(92)90003-C

Tran, C.T.H., N. Cassoux, B. Bodaghi and P. Lehoang, 2003a. Successful treatment with combination of systemic antiviral drugs and intravitreal ganciclovir injections in the management of severe necrotizing herpetic retinitis. Ocul. Immunol. Inflamm., 11: 141144. PMID: 14533033

Tran, T.H., F. Rozenberg, N. Cassoux, N.A. Rao, P. LeHoang and B. Bodaghi, 2003b. Polymerase chain reaction analysis of aqueous humour samples in necrotising retinitis. Br. J. Ophthalmol., 87: 79-83. PMID: 12488268

TSOCAIDSRGCAIDSCTG, 2000. Long-term follow-up of patients with AIDS treated with parenteral cidofovir for cytomegalovirus retinitis: The HPMPC Peripheral Cytomegalovirus Retinitis Trial. Aids, 14: 1571-1581. PMID: 10983644
Urayama, A., N Yamasa and T. Sasaki, 1971. Unilateral acute uveitis with retinal periarteritis and detachment. Jpn. J. Clin. Ophthalmol., 25: 607-619.

Vrabec, T.R. 2004. Posterior segment manifestations of HIV/AIDS. Surv. Ophthalmol., 49: 131-157. DOI: 10.1016/j.survophthal.2003.12.008

Vrabec, T.R., V.F. Baldassano and S.M. Whitcup, 1998. Discontinuation of maintenance therapy in patients with quiescent cytomegalovirus retinitis and elevated CD4+ counts. Ophthalmology, 105: 12591264. DOI: 10.1016/S0161-6420(98)97031-2

Walker, S., A. Iguchi and N.P. Jones, 2003. Frosted branch angiitis: A review. Eye Lond, 18: 527-533. DOI: $10.1038 /$ sj.eye.6700712

Walters, G. and T.E. James, 2001. Viral causes of the acute retinal necrosis syndrome. Curr. Opin. Ophthalmol., 12: 191-195. PMID: 11389345

Wei, L.L., S.S. Park and D.J. Skiest, 2002. Prevalence of visual symptoms among patients with newly diagnosed cytomegalovirus retinitis. Retina, 22: 278-282. PMID: 12055459

Wentworth, B.B. and E.R.A. Ander, 1971. Seroepidemiology of infectious due to members of the herpesvirus group. Am. J. Epidemiol., 94: 496-507.

Yoshihiko, U. and G. Hiroshi, 2008. Overview and diagnosis of acute retinal necrosis syndrome. Semin. Ophthalmol., 23: 275-283. PMID: 18584564

Young, N.J. and A.C. Bird, 1978. Bilateral acute retinal necrosis. Br. J. Ophthalmol., 62: 581-590. DOI: 10.1136/bjo.62.9.581 